\title{
UWB Transmission through Human Thorax: An Index of Cardiac Health
}

\author{
https://doi.org/10.3991/ijoe.v16i13.18593 \\ Kedar Nath Sahu ${ }^{(凶)}$ \\ Stanley College of Engineering and Technology for Women, Hyderabad, India \\ knsahu72@egmail.com \\ Challa Dhanunjaya Naidu \\ VNR Vignana Jyothi Institute of Engineering and Technology, Hyderabad, India \\ Jaya Sankar Kottareddygari \\ Mahatma Gandhi Institute of Technology, Hyderabad, India
}

\begin{abstract}
There are many applications which require remote and noninvasive measurement of heartbeat of a human being using an ultra-wideband (UWB) radar. Sophisticated models and their analysis need to be referred before the design of a practical radar prototype. In this paper, i) a UWB wave propagation model of human thorax and ii) the power transmission coefficients estimated from the simulations of the model in the range $1-10 \mathrm{GHz}$ using MATLAB are presented. The study reveals that there is a periodic variation of the transmission coefficients in correlation with the instantaneous physical dimensions of an active heart.
\end{abstract}

Keywords-Human heartbeat, tissue dielectric properties, ultra-wideband, transmission coefficient

\section{$1 \quad$ Introduction}

There are several applications like health monitoring of a patient, criminal investigation, search operations and so on which are based on remote detection of heartbeat of a human being. In this connection, use of radars is inevitable as they can provide non-invasive measurements by placing the radar at a distant location away from the subject under investigation. In recent years, ultra-wideband (UWB) radars have been found more feasible for assessment of human life-signs due to numerous advantageous features [1-3]. UWB radar models describing heartbeat detection with direct exposure of human being to UWB signal have been reported in [4-15]. Experimental setups for UWB radar-based heartbeat measurements are mentioned in [16-19].

The objective of this work is to investigate for possible detection of human heartbeat from the UWB signal transmission characteristics. Therefore, the UWB transmission coefficients are estimated from a planar multilayered structure of the human thorax using MATLAB. The calculations of the transmission coefficients of the UWB 
signal have been performed considering the frequency dependent properties of various layers and the multiple reflections that take place at the boundaries. The basic characteristic of heart, namely, the heartbeat rate essentially depends on the variation of heart dimensions. It has been shown conclusively that the UWB transmission characteristic obtained at selected specific frequencies is an index of the heartbeat rate, thus leading to the possibility of using the transmission coefficient as a parameter to know the health of heart.

\section{Signal Transmission Analysis}

The analysis of UWB transmission is based on the wave propagation through a planar model of multilayered dielectrics. The analysis is carried out by calculating the incident and transmitted powers at any interface due to a net forward wave caused by multiple reflections at various interfaces. The transmitted power is calculated after considering the multiple reflections occurring at all the boundaries. The net transmitted power $[20,21]$ to the right of every tissue interface are analytically calculated at specific frequencies of the UWB using (1).

Net transmitted power

$$
P_{t}=\left(1-|\Gamma|^{2}\right) P_{i}
$$

Where Pi is the net incident power and $|\Gamma|$ is the magnitude of the complex electric field reflection coefficient at an interface of any two consecutive layers of materials. The general procedure of calculating transmission coefficients is outlined below.

\subsection{Transmission coefficient}

The transmission coefficient of a signal through a multilayer structure depends essentially on the sum of the losses occurring when i) the wave propagates through each layer of the material and ii) the wave gets reflected at the interface of the layers. The amplitude of the electromagnetic signal reduces while propagating through the successive layers of a multilayer system. As explained in [22], transmission coefficient $(\mathrm{dB})$ is mathematically defined as

$$
\text { Transmission coefficient }=10 \log _{10} \frac{\text { transmitted power wave at output end, } \mathrm{P}_{\mathrm{t}}}{\text { incident power wave at input end, } \mathrm{P}_{\mathrm{i}}}
$$

Considering normal incidence of a plane wave at the interface of the first layer, the fraction of the incident power that is transmitted to the other side of the entire layer system is obtained by including the effects of attenuation of the waves transmitted at every interface of the layers as described in [20,21]. The net transmitted power coefficient at the output is determined by multiplying the:

i. Square of the magnitude of the product of transmission coefficients as given by (3) and 
ii. Product of attenuation factors of all the layers as given by (5).

The magnitude square of the product of transmission coefficients is given by

$$
T_{(f p)}=\left|\tau_{1} \tau_{2} \tau_{3} \tau_{4} \ldots \ldots \ldots \tau_{n}\right|^{2}
$$

where $\tau_{n}=$ power transmission coefficient at $\mathrm{n}$-th interface

$$
=1-\left|\Gamma_{n}\right|^{2}
$$

The product of attenuation factors can be expressed as

$$
A_{(f p)}=e^{-2 \alpha_{2} \ell_{2}} e^{-2 \alpha_{3} \ell_{3}} e^{-2 \alpha_{4} \ell 4} \ldots \ldots \ldots e^{-2 \alpha_{n} \ell_{n}}
$$

where $\alpha_{n}=$ attenuation constant corresponding to the n-th layer.

Therefore, the net transmitted power as would be measured by a receiver placed at the end of the thorax is given by

$$
P_{t}=T_{(f p)} \times A_{(f p)} \times P_{i}
$$

From (4) it is clear that the complex E-field reflection coefficient, $\left|\Gamma_{n}\right|$ is fundamental in the calculation of the net transmitted power. Hence, their values can be calculated at every interface of a multilayer system using the impedance transformation method described in $[20,21]$. The expressions for the effective impedance at the interfaces are obtained by using the boundary conditions at every interface taking into account the total effect due to multiple reflections. For a four-layer three-interface planar model shown in Figure 1 the values of effective or input impedance $\eta_{i n, 3}$, $\eta_{i n, 2}$ and $\eta_{i n, 1}$ (at the interfaces $\mathrm{n}=3,2$ and 1 , respectively) are given by the expressions (7) through (9), respectively.

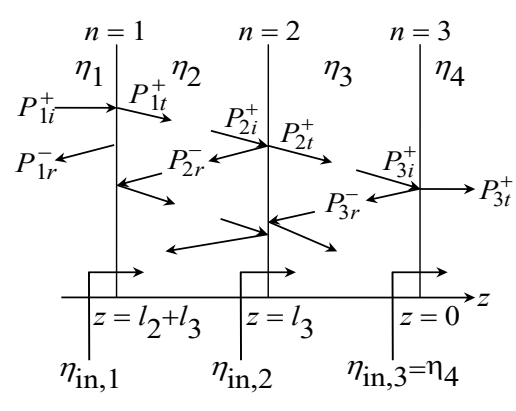

Fig. 1. Planar four-layer model

$$
\eta_{i n, 3}=\eta_{4}
$$




$$
\begin{gathered}
\eta_{i n, 2}=\eta_{3} \frac{\eta_{4} \cos \beta_{3} l_{3}+j \eta_{3} \sin \beta_{3} l_{3}}{\eta_{3} \cos \beta_{3} l_{3}+j \eta_{4} \sin \beta_{3} l_{3}} \\
\eta_{i n, 1}=\eta_{2} \frac{\eta_{i n, 2} \cos \beta_{2} l_{2}+j \eta_{2} \sin \beta_{2} l_{2}}{\eta_{2} \cos \beta_{2} l_{2}+j \eta_{i n, 2} \sin \beta_{2} l_{2}},
\end{gathered}
$$

where $\eta_{1}, \eta_{2}, \eta_{3}$ and $\eta_{4}$ are the intrinsic impedances; $\beta_{2}$ and $\beta_{3}$ are the phaseshift constants; $l_{2}$ and $l_{3}$ denote the thickness of the corresponding layers. The input impedance represents the effective impedance offered by all the successive layers to the right of that interface. In general, reflection coefficient at the n-th interface of a multilayered model having $(\mathrm{n}+1)$ layers is given by

$$
\Gamma_{n}=\frac{\eta_{i n, n}-\eta_{n}}{\eta_{i n, n}+\eta_{n}}
$$

where $\eta_{i n, n}$ denotes the input impedance at the n-th interface and $\eta_{n}$ represents the intrinsic impedance of the $n$-th layer of the planar multilayer model.

From the above discussion, it may be concluded that, the input impedance at any interface in a layered medium obtained using the impedance transformation method is a function of the propagation length 1 . Hence, the thickness of the layers associated with a multilayer model is a factor that influences this impedance. Consequently, the transmission coefficients obtained using the impedance transformation method also vary with the thickness of the layers. Following this analytical treatment for a planar layered structure, the investigations about the transmission characteristics, when a human body is illuminated by planar UWB wave, is carried out. This is done by modelling the human thorax as a series of biological tissue layers with frequency dependent dielectric properties.

\section{$3 \quad$ Modelling of Human Thorax}

Considering selected biological tissues such as skin, fat, muscle, cartilage, lungs and heart, a one-dimensional model, with reference to the Visible Human Project [23], has been constructed as depicted in Figure 2. The human thorax structure [14] enclosing the heart has been organized into several layers of tissues from the chest skin up to the posterior skin. It is assumed that all tissues except heart, have the fixed dimensions, which are referred by the numerical values in Figure 2.

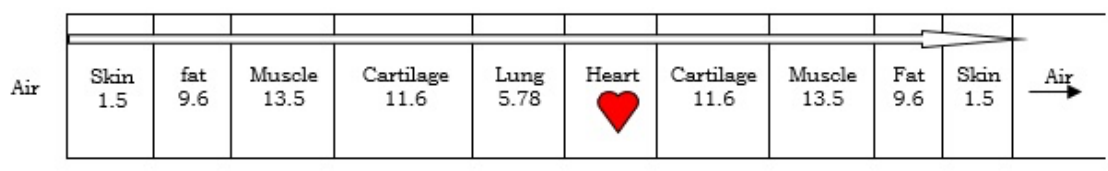

Fig. 2. Tissue structure of the human thorax model 
On illumination of a UWB microwave signal on the thorax, various tissues are encountered in the signal path with skin being the first tissue interface. The signal propagates through the pulsating heart and comes out at the back of the human body. A beating heart undergoes change of its longitudinal dimension instantaneously [24] during systole (up to $0.3 \mathrm{~s}$ ) and diastole $(0.3-0.8 \mathrm{~s}$ ) of every cardiac cycle of total period of $0.8 \mathrm{~s}$. Considering those parts of the heart [Figure 3] which undergo remarkable change of dimensions during its beating, the instantaneous heart dimensions as calculated in [15] for one cardiac cycle of $0.8 \mathrm{~s}$ is depicted in Figure 4.

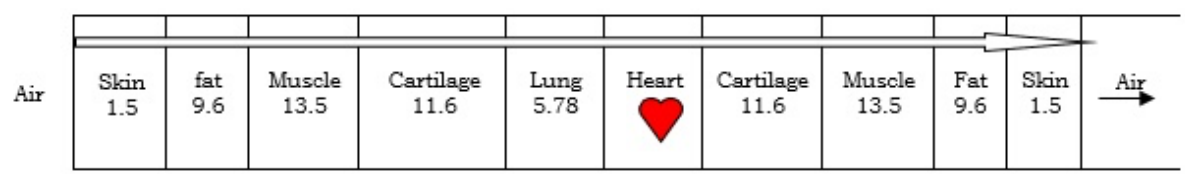

Fig. 3. Transverse section of human heart

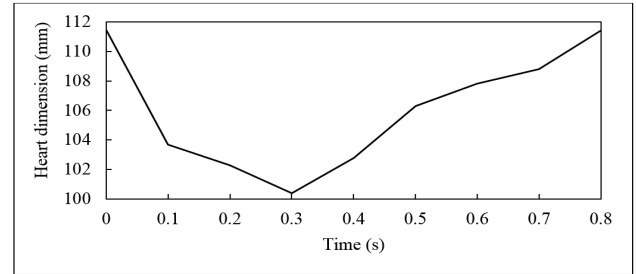

Fig. 4. Variation of instantaneous dimension of heart with time during a cardiac cycle

As dielectric properties of tissues vary with frequency, the electromagnetic propagation model in this work is constructed using the dispersive dielectric properties such as the permittivity, permeability, and conductivity based on the Cole-Cole model provided in the Gabriel's data book [25]. The value of permeability is considered as one for the entire band of frequencies.

Assuming normal incidence of a planar wave, the simulations are performed using MATLAB, for the planar multilayered EM model at specific frequencies in the UWB range $1-10 \mathrm{GHz}$ and corresponding to the specific instants of the cardiac cycle. The values of transmission coefficients obtained from the simulations at these specific frequencies are plotted. The simulation results are presented in Section 4.

\section{$4 \quad$ Simulation Results and Discussion}

Simulation Results: The simulations based on the realization of the mathematical expressions (3)-(10), for the EM power transfer across the interfaces of the multilayered model are carried out and the transmission coefficients are calculated at a specific frequency. The transmission coefficients $(\mathrm{dB})$ were calculated for the varying dimensions of heart [Figure 4] over one cardiac cycle using MATLAB. Their varia- 
tions with time in one cardiac cycle at specific frequencies in the UWB range 1-10 GHz are shown in Figure 5 (a) through (s).

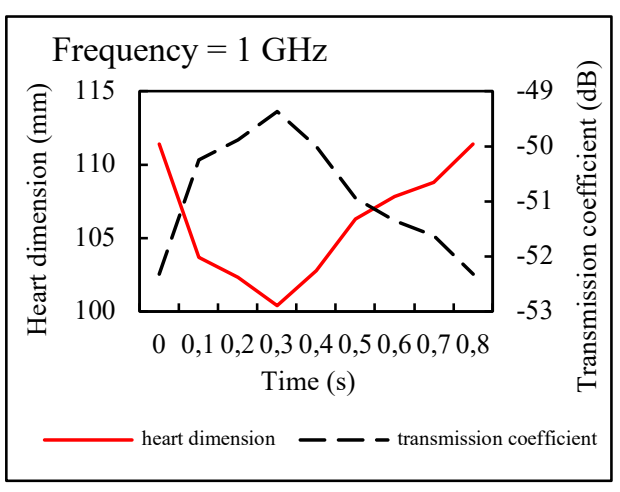

a)

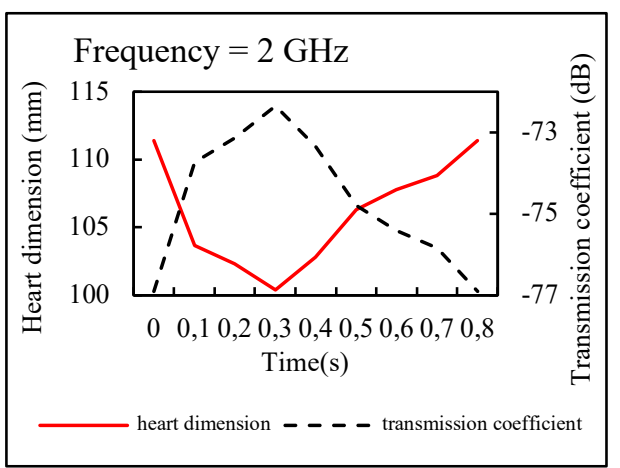

c)

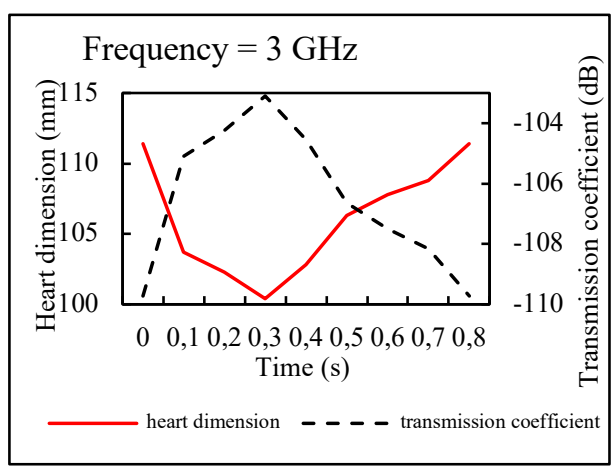

e)

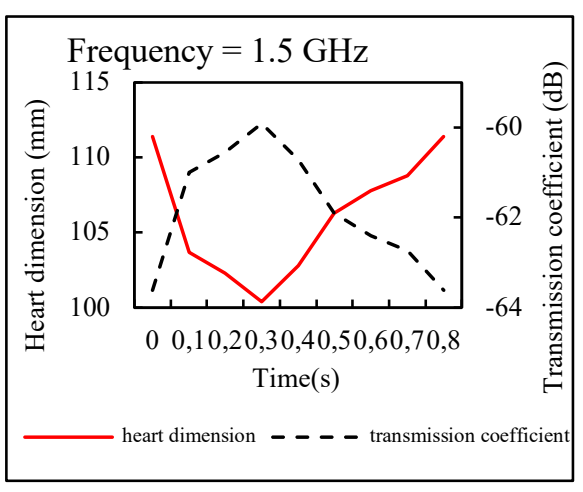

b)

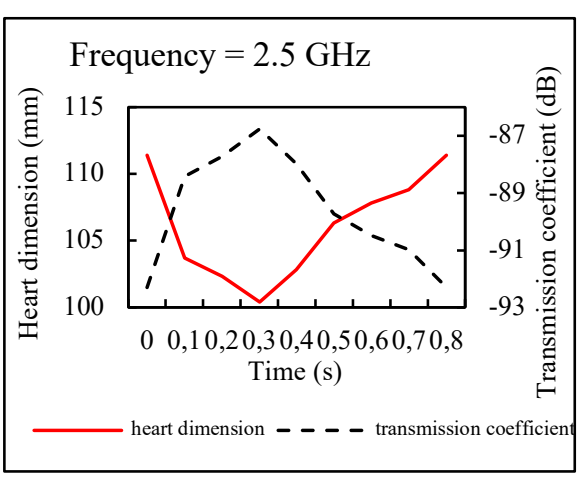

d)

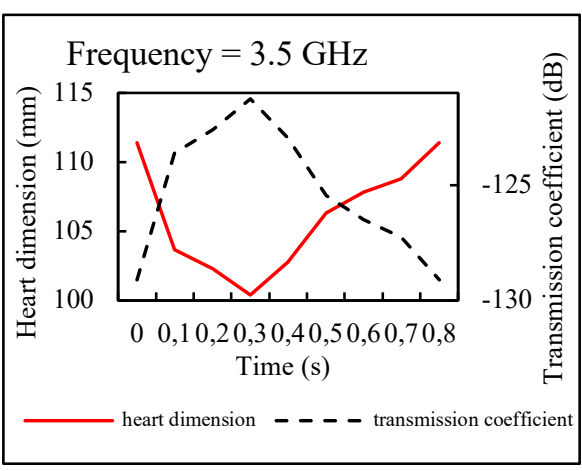

f) 


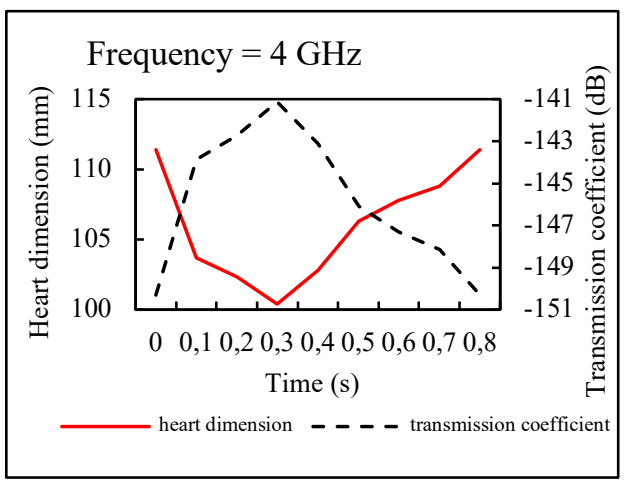

g)

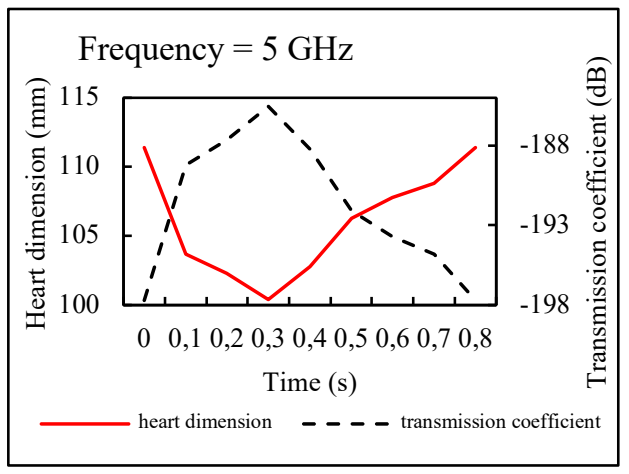

i)

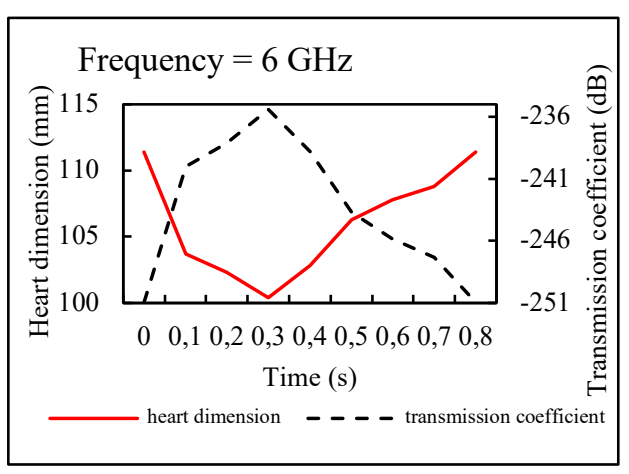

$\mathrm{k})$

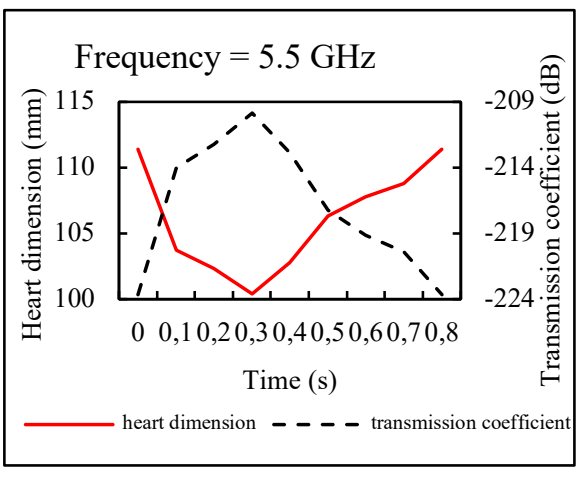

h)

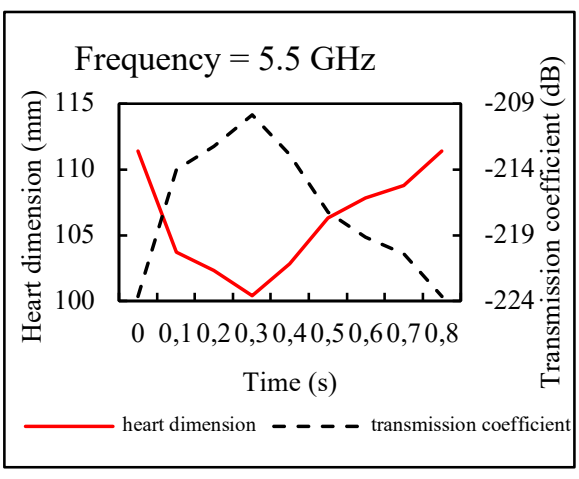

j)

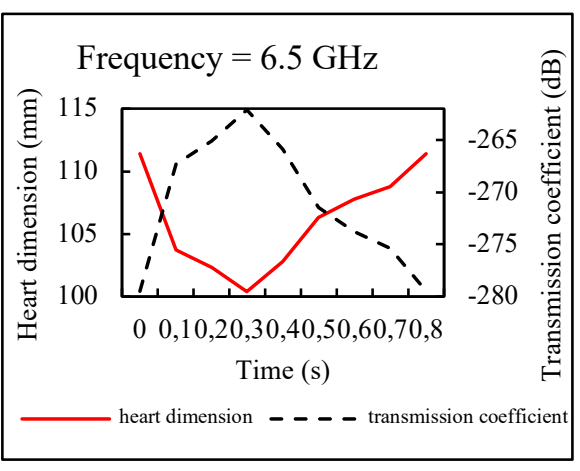

1) 


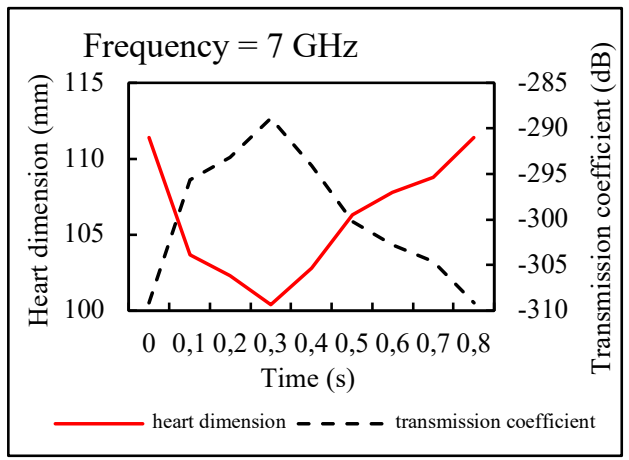

m)

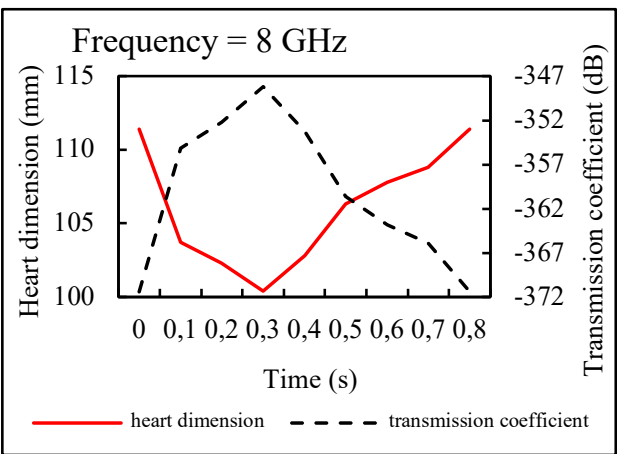

o)

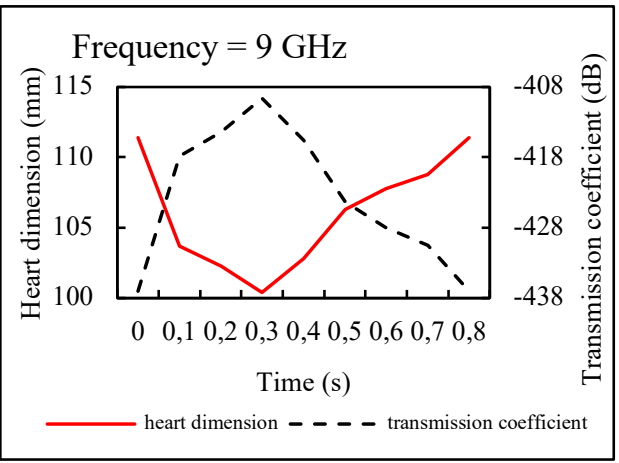

q)

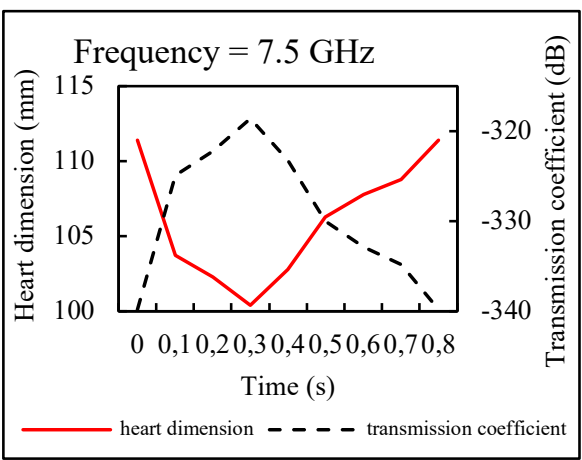

n)

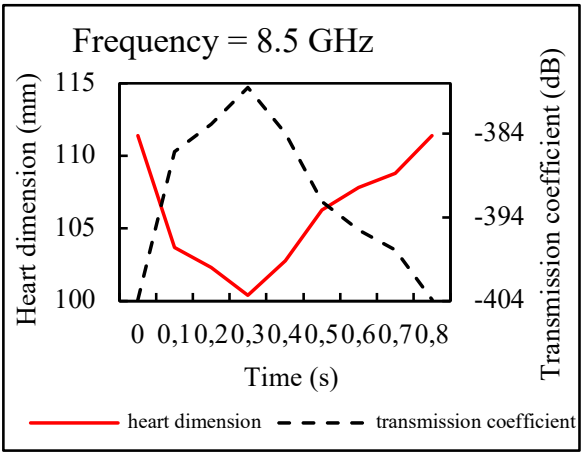

p)

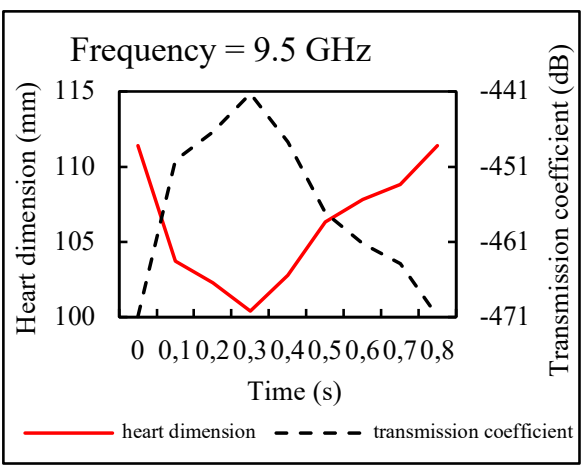

r) 


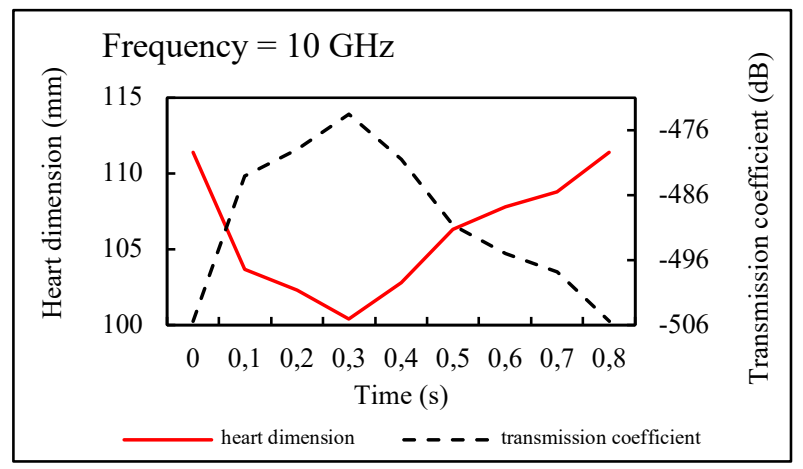

s)

Fig. 5. Variation of transmission coefficient with heart dimension in a cardiac cycle at specific frequencies in the range $1-10 \mathrm{GHz}$

Discussion: It is seen from the simulations at every specific frequency in the UWB range 1-10 GHz that, the transmission coefficients increase during systole, become maximum at $0.3 \mathrm{~s}$ (instant at which the heart is completely contracted) and decrease during diastole. Thus, there is a unique trend of variation of the transmission coefficients with the physical dimension of the heart in a complete cardiac cycle. This observation is unique in that the transmission coefficient $(\mathrm{dB})$ of heart corresponds to its instantaneously varying dimension during every cardiac cycle.

Thus, the study reveals that the trend of variation of the transmission coefficients following that of the instantaneous physical dimensions of the heart during successive heartbeats can be used as an index of the health of heart of a human being.

\section{Conclusion}

From the investigations carried out using the planar multilayered human thorax model, it is observed that the variation of transmission coefficients follow the dimensional variations of a beating heart at all instants of a cardiac cycle. There is a periodic variation in the transmission coefficients of an active heart calculated at the specific frequencies in the UWB from 1-10 GHz. The periodicity between two consecutive maxima or minima refers to the heartbeat period. Lack of periodicity would refer to as the sign of an unhealthy heart.

\section{Acknowledgement}

The authors are grateful to Dr. Ravindharan Ethiraj, Professor (Retired), Department of Physics, Osmania University, Hyderabad, India and Shri Paramananda Jena, Scientist-F, Electronic and Radar Development Establishment (LRDE)-DRDO, Bengaluru, India for their academic support. 


\section{$7 \quad$ References}

[1] Taylor, J. D. (1995). Introduction to ultra-wideband radar systems, CRC Press, Boca Raton, FL.

[2] Immoreev, I., Dmitry, P. G. S.,\& Fedotov, V. (2002). Ultra-wideband radar systems: advantages and disadvantages, IEEE Conf. Ultra-Wideband Syst. and Technol., 18: 201205.https://doi.org/10.1109/uwbst.2002.1006348

[3] Immoreev, I. (2006). Practical application of ultra-wideband radars, Proc. Ultra-wideband and Ultra-short Impulse Signals. https://doi.org/10.1109/uwbus.2006.307156

[4] Staderini, E.M. (2002).UWB radars in medicine, IEEE Aerosp. Electron. Syst. Mag., 17(1):13-18.https://doi.org/10.1109/62.978359

[5] Immoreev, I.Y.,Samkov, S.\& Tao, T.H. (2005). Short-distance UWB radars, IEEE Aerosp. Electron. Syst. Mag., 20(6): 9-14.https://doi.org/10.1109/maes.2005.1453804

[6] Bilich, C.G. (2006). Bio-medical sensing using ultra-wideband communications and radar technology: A feasibility study, Pervasive Health Conf. and Workshops 2006, 29:19.https://doi.org/10.1109/pcthealth.2006.361671

[7] Rivera, N.V., Venkatesh, S., Anderson, C. \& Buehrer, R.M. (2006). Multi-target estimation of heart and respiration rates using ultra-wideband sensors, 14th European Signal Process. Conf., Florence, Italy, pp.1-6.

[8] Bilich, C.G. (2007). Feasibility of dual UWB heart rate sensing and communications under FCC power restrictions, 3rd Int. Conf. Wireless and Mobile Commun. 2007 (ICWMC 2007), Guadaloupe, French Caribbean.

[9] Staderini, E.M.\&Varotto, G. (2007). Optimization criteria in the design of medical UWB radars in compliance with the regulatory masks, IEEE Biomed. Circuits Syst. Conf. (BIOCAS 2007), Montreal, Que, pp. 53-58. https://doi.org/10.1109/biocas.2007.4463307

[10] Berger, T.,Hamran, S.E., Hanssen, L.\& Øyan, M.J. (2008).Ultra-Wideband Radar Design for Detection of Vital Signs, NATO-RTO/SET-125 Symp. Defence Against Terrorism, April 2008.

[11] Immoreev, I. \& Tao, T. H. (2008). UWB radar for patient monitoring, IEEE Aerosp. Electron. Syst. Mag., 20:11-18.https://doi.org/10.1109/maes.2008.4693985

[12] Pisa, S.,Bernardi, P.,Cavagnaro, M.,Pittella, E. \&Piuzzi, E. (2008). Monitoring of cardiopulmonary activity with UWB radar: a circuital model, Proc. 2008 Asia-Pacific Symp. Electromagn. Compatibility and 19th Int. Zurich Symp. Electromagn. Compatibility, Singapore, pp. 224-227. https://doi.org/10.1109/apemc.2008.4559852

[13] Yarovoy, A.G.,Ligthart, L.P.,Matuzas, J.\&Levitas, B. (2008). UWB radar for human being detection, IEEE Aerosp. Electron. Syst. Mag., 23 (5): 36-40.https://doi.org/10.1109/maes. 2008.4523914

[14] Cavagnaro, M.,Pittella, E.\& Pisa, S. (2013). UWB pulse propagation into human tissues, Phys. Med. Biol., 58: 8689 - 8707.https://doi.org/10.1088/0031-9155/58/24/8689

[15] Sahu, K.N., Naidu, C.D., Satyam, M. \& Jaya Sankar, K. (2015). Study of RF signal attenuation of human heart, J. Eng., Hindawi Publishing Corporation, 1-8, 2015, doi: $10.1155 / 2015 / 484686$.

[16] Venkatesh, S., Anderson, C., Rivera, N.V.\& Buehrer, R.M. (2005). Implementation and analysis of respiration-rate estimation using impulse-based UWB, Proc. IEEE Military Communications Conf. (MILCOM '05), Atlantic City, NJ, USA, Vol. 5, pp. 3314 3320.https://doi.org/10.1109/milcom.2005.1606167

[17] Lazaro, A.,Girbau, D. \&Villarino, R.(2010). Analysis of vital signs monitoring using an IR-UWB radar," Progress in Electromagnetics Research, 100: 265-284.https://doi.org/10. $\underline{\text { 2528/pier09120302 }}$ 
[18] Bernardi, P., Cicchetti, R., Pisa, S.,Pittella, E.,Piuzzi, E. \& Testa, O. (2014). Design, realization, and test of a UWB radar sensor for breath activity monitoring, IEEE Sensors Journal, 14 (2): 584-596. https://doi.org/10.1109/jsen.2013.2285915

[19] Pittella, E., Bottiglieri, A., Pisa, S., \&Cavagnaro, M. (2017). Cardiorespiratory frequency monitoring using the principal component analysis technique on UWB Radar Signal, Int. J Ant. Propag., 1-6. https://doi.org/10.1155/2017/4803752

[20] Hayt, W.H.\&Buck, J.A. (2006). Engineering Electromagnetics, 7th ed., India: Tata McGraw-Hill.

[21] Inan, U.S. \&Inan, A.S. (2010). Engineering Electromagnetics, 1st ed. India: Pearson Education Inc.

[22] Pozar, D.M.(2012).Microwave Engineering, 4th ed., USA: John Wiley \& Sons, Inc.

[23] Chang, Y.J. (1997). The NPAC visible human viewer, Syracuse University, New York.

[24] Gibson, D.G., Trail, T.A. \& Brown, D.J. (1977). Changes in left ventricular free wall thickness in patients with ischaemic heart disease, British Heart J., 39:1312-1318. https://doi.org/10.1136/hrt.39.12.1312

[25] Gabriel, C. (1996). Compilation of the dielectric properties of body tissues at RF and microwave frequencies," Occupational and environmental health directorate, radio freq. radiation division, Brooks Air Force Base, Texas, USA. Rep. N.AL/OE-TR-19960037.https://doi.org/10.21236/ada303903

\section{Authors}

Kedar Nath Sahu, Professor, Department of Electronics and Communication Engg., Stanley College of Engineering and Technology for Women, Hyderabad, India, received the professional engineering degrees in Electrical Engineering (1996) and Electronics and Communication Engineering (2001) from The Institution of Engineers (India) and M.Tech. (2002) from Visvesvaraiah Technological University, Karnataka, India. He received Ph.D. Degree in Electronics and Communication Engineering from Jawaharlal Nehru Technological University Hyderabad (JNTUH), Hyderabad in 2017. He has over 18 years of experience in teaching, in the faculty of Electronics and Communication Engg. His research interests include Applied Electromagnetics, Biomedical Engineering, Microwave and Radar Engineering. He is Fellow IETE, IE (India) and Life Member of ISTE.

Challa Dhanunjaya Naidu, Professor, Department of Electronics and Communication Engg., VNR Vignana Jyothi Institute of Engineering and Technology, Hyderabad, India received B.Tech. in Electronics and Communication Engg. (1982) and M.Tech. Degree (1985) from the College of Engineering, S. V. University, Tirupati, Andhra Pradesh, India. He earned his Ph.D. Degree in Electronics and Communication Engg. from JNTUH, Hyderabad. His research interests include Signal Processing, Image Processing, and Neural Networks. He is a Fellow of IE (India), IETE and Life Member of ISTE.

Jaya Sankar Kottareddygari, Professor, Department of Electronics and Communication Engg., and Principal, Mahatma Gandhi Institute of Technology, Hyderabad, India, received B.Tech degree in Electronics and Communication Engg. from S. V. University, Tirupati, India and M.E. and Ph.D. degrees from the Department of Electronics and Communication Engg., Osmania University, Hyderabad, India in 1988, 
1994, and 2004 respectively. He has 27 years of experience in teaching Electromagnetics, Antennas and Wave Propagation, Digital Communication and Microwave and Radar Engg. His research areas of interest are in Coding Theory, RF and Wireless Communications and Genetic Algorithm based antenna design. He is a Senior Member IEEE, Fellow of IETE and IE (India), Life member of SEMCE (India) and ISTE.

Article submitted 2020-09-15. Resubmitted 2020-10-01. Final acceptance 2020-10-01. Final version published as submitted by the authors. 